\title{
Information Systems Management in the Small Liberal Arts College
}

\begin{abstract}
As curricula change on the undergraduate campus the college library faces problems in meeting the changed information demands being made upon it. To understand these problems better a research project funded by the National Science Foundation was begun in 1967 at Hamline University. The study concluded that the undergraduate library must become more of an information switching center, which both identifies and meets the information needs of its clientele. A pilot switching center is now being developed at Hamline University, again funded by the National Science Foundation, to develop techniques for effectively meeting campus information needs.
\end{abstract}

$\mathrm{F}$ ROM 1964 To 1966 the library staff of Hamline University accumulated considerable evidence that its campus library was not meeting the needs of its institution's educational program. There were several environmental changes which seemed to have been contributants to inadequacies of the library.

The college library was expected to provide more periodical and book titles than ever before. But even the provision of a meaningful collection of core materials has become economically more difficult because of the wider range of published materials from which to select. Changes in the faculty are likely to require a completely different collection of library materials to support new courses. Faculty members both new and old place greater reliance on periodical articles, which has required the strengthening of periodical collections, includ-

Mr. Johnson is Librarian and Mr. King is Head of Technical Services in the Hamline College Library. ing publications available in reprint and microform editions.

Materials required for college subjects also increased in both depth and breadth. A gradually changing curriculum was placing more emphasis on library research in some subject areas. The development of individualized study programs, under the general label of "independent study," meant that the students were in need of materials previously considered beyond the scope of the college library. For example, college libraries have seldom included source material in their collections for history students, relying instead on interpretative monographs. With the advent of independent study programs some history students found themselves in need of a variety of source materials which the campus library was ill-equipped to provide.

The library staff also became aware of the inadequacies of the bibliographic control systems which they provided. The card catalog, based on Library of 
Congress cataloging, was not without its shortcomings. Subject headings were outdated and frequently too general to be of significant use to students. Also, too many periodical indexes were issued too slowly to meet the needs of many students. Finally, there was no satisfactory method of locating materials which might be used by students in the metropolitan area of the Twin Cities of Minneapolis and St. Paul, an area which includes seven college libraries, a university library system of over two million volumes and many nonacademic libraries.

Serious as these problems were, the library staff found itself hampered in defining basic problems and exploring solutions, because of the time requirements of daily operations. In an effort to find a way of defining basic problems the authors submitted a proposal to the National Science Foundation.

In the grant proposal the problems were summarized thus:

The small, liberal arts college library is becoming less and less adequate to fulfill the complex and expanding requirements of its user groups. New information sources and services increase the scope and variety of the information environments in which the small, liberal arts college is embedded. New directions and more sophisticated solutions are required if the small, liberal arts college is to keep pace with the information explosion. ${ }^{1}$

The study was to be accomplished as five interrelated tasks:

1. describe present state of the critical variables;

2. project future characteristics of users and external services;

${ }^{1}$ Information Systems Management in the Small, Liberal Arts College: Problems, Trends, and Potential Solutions. November, 1966. Submitted by: Hamline University, St. Paul, Minnesota 55101. Initiated by: Hamline University Library. Principal Investigators: Herbert F. Johnson, Head Librarian. Jack B. King, Head, Technical Services. Submitted to: National Science Foundation. p. ii.
3. define requirements, constraints, and criteria for future system;

4. generate potential solution concepts for Hamline information system;

5. evaluate potential solution concepts.

\section{Methodology}

The contract researchers, working under the direction of the principal investigators, developed a methodology which they believed would accomplish the five tasks. Their procedures and techniques were divided into three broad areas:

1. a classification of major sources of study data;

2. an identification of alternative techniques for obtaining data from various sources;

3. a description of some probable procedures that would be used to process the obtained study data.

Two sources of data were tapped: personnel sources and written sources. Three personnel sources of data were identified: (1) "Those individuals who are identified as users of the defined information system; (2) those individuals who are knowledgeable regarding sources of information within the selected study scope; (3) those individuals who are knowledgeable regarding procedures for obtaining system information."2 Five classes of written sources of information were identified: (1) documents describing Hamline University information sources, content, and procedures for retrieving information; (2) reports concerning studies done on the adequacy of the current information system; (3) planning papers of various faculty committees describing mid- and long-range plans for Hamline University; (4) documents describing ongoing or planned projects and programs in the

${ }^{2}$ Ibid., p. 7. 
local area which contribute to the current information system; (5) materials describing the capabilities, facilities, and experiences of local companies, colleges, and contractors in the broad area of technical and scientific knowledge and information.

The contract researchers decided to rely on interviews as the basic technique for obtaining data. Three interview techniques were used to varying degrees during the research program:

1. Unstructured interview. The researchers characterized this as "generally 'open ended' and the interviewee is not restricted to any particular set of responses."

2. Critical incident interview. "The interviewee would be asked to select a situation in obtaining needed information."

3. Structured interview. "The interviewee responses are usually restricted to ranking or rating a prepared list of factors found to be significant with respect to performance of the user."3

In order to process the data obtained during the study the researchers decided to apply three "basic system-derived methods":

1. Descriptive model construction. The researchers anticipated a need to develop a number of descriptive models which would "portray key elements associated with each user-information-interface subsystem."

2. Projection of requirements. " ... the objective will be to determine future information system needs, user roles, and interface requirements to meet these future projections."

3. Simulation studies. "Proposed solutions will have to be evaluated prior to being rejected or recom-

${ }^{3}$ Ibid., p. 8. mended. Simulation provides a useful system tool for examining alternative concepts for correcting either deficiencies in user knowledge, gaps in the information system, or inefficiencies in the user/system interface." ${ }^{4}$

\section{Summary of Results}

The comparability of the study of any particular library to others of its class is very difficult to achieve in an objective way. General statistics collected by and for the library profession are neither detailed nor standardized enough to make such comparisons. However, the campus library of Hamline University by size of collection, staff, and provided services is probably very typical of its particular class. Any deviations from the norm probably occur in the following areas:

1. Better faculty-library relations than are to be found on most campuses. The professional staff has pursued a policy for the past two years of actively improving liaison with the faculty in an effort to integrate more closely the library with the educational program of the school.

2. A more sophisticated use of professional and clerical staff than is common in academic libraries.

3. Extremely crowded physical conditions which are not conducive to efficient processing operations nor attractive to the users.

4. A rate of growth which probably has lagged behind the rate of growth for the college generally. Growth here is broadly defined as improvement of programs and not simply as increased enrollment or acquisition rate, although these are factors.

5. An active concern of many of the faculty that the campus library is not adequate for the educational program of the school.

4 Ibid., p. 9. 
The research effort was directed primarily at attempting to determine whether there was any basis in fact for the opinion of the professional staff that the campus library was playing a less significant role in the educational program of the school than seemed desirable. The best approach to the problem was, naturally, a quantification of the role which the campus library played on campus. As a preliminary study, taking place within one year, the researchers were unable to quantify completely the factors which relate to the significance of a library operation. This inability was due to the fact that very little work has been done by the profession in the past to establish reliable, statistical indicators for such factors, and the amount of time necessary to establish them was not available.

Evidence was gathered, however, which indicated interesting results in three different areas. The evidence indicated that on the Hamline campus the more sophisticated the library user, the less his dependence on the campus library. This result seems to corroborate the studies of scientist users. The study also indicated that the communication channels between the campus librarians and the faculty were inadequate. Finally, there is a need for more effective and timely control of information at the undergraduate level of education.

The contract researchers conducted an interviewing program which included 60 per cent of the faculty, sixteen honors and independent study students, and eighteen "regular" students who had never registered for honors or independent study projects. The sampling of the faculty was statistically significant, while the sampling of students was not statistically significant. The majority of students were selected on the basis of their being heavy library users.

The six top sources of information used and the percentage of faculty us- ing each were: professional meetings, 60 per cent; University of Minnesota library (the main library is three miles distant from the Hamline campus), 50 per cent; campus departmental libraries, 27 per cent; Hill Reference Library (a non-circulating reference library in St. Paul, three miles distant from the Hamline campus), 21 per cent; campus main library, 19 per cent; colleague's collections, 15 per cent.

It is not surprising that the campus library does not play a greater role in providing faculty information, since the traditional policy of college libraries has been to provide only support to the undergraduate program. It is interesting, however, to note that a library is not the most common channel for obtaining information among the faculty, and it is also interesting to note the use of their colleague's collection as sources of information. These results seem to agree generally with those reported by other researchers. Donald P. Hammer, in "National Information Issues and Trends," reported on "the indifference of scientists and technologists toward the use of information centers and libraries. This lack of use compounds the national information problem in that scientists are not only flooded with data that lacks good bibliographic control, but they apparently do not use the existing facilities that can provide some relief." 5

Among the students a considerable difference was noted in the way in which the honors and independent study students sought information, and the way in which "regular" students on campus met their information needs. The honors-independent study students, faced with an in-depth research project which required considerable library use, seemed to find the campus library of less help than might be expected. Following, in ranked order, are the most

\footnotetext{
s Donald P. Hammer, "National Information Issues and Trends," Annual Review of Information Science and Technology, v. 2. p. 389 .
} 
commonly used collections among honors-independent study students: main library, 56 per cent; Hill Reference Library, 44 per cent; professor's personal collection, 38 per cent; University of Minnesota library, 38 per cent; St. Paul Public Library, 31 per cent. Yet libraries as sources of information did seem to be of more importance to such students than to their professors. It is also interesting to note that their professors' collections ranked at the same level as the University of Minnesota library.

The "regular" students fit a pattern of usage that one could anticipate. But even so, the students used a variety of collections: main library, 72 per cent; St. Paul Public Library, 61 per cent; professor's personal collection, 39 per cent; Minneapolis Public Library, 39 per cent; campus department libraries, 33 per cent; Hill Reference Library, 33 per cent. While the student sample is small, it does suggest that the "regular" students probably were looking for assigned readings and secondary material to support assigned term papers. While the St. Paul and Minneapolis Public Libraries are good examples of their type, their collections cannot support research in many subject areas. ${ }^{6}$

The data collected also indicated another interesting phenomenon. Although the professional staff of the campus library has pursued a policy of establishing close communications with the faculty, the program still has much to accomplish. This program has consisted not only of informal contacts such as various social occasions, coffee breaks, working lunches, and committee assignments, but also a program of formal communication. For the last two years the librarians have scheduled meetings with each full-time faculty member to discuss any library problems he may

${ }^{6}$ A discussion with the staff of the St. Paul Public Library corroborated the indication that student users were looking for assigned readings. have. Such meetings usually occur in the faculty office. While this program is somewhat unusual in academic libraries, the data indicates that very basic communication improvements still need to be made with the faculty. As the Schumacher report states, "The faculty and students appear to be generally unaware of current library holdings and services and of how best to make use of these facilities and services." 7 Two excerpts from the Schumacher report based on interviews indicated information problems. For the faculty the report stated:

All of the faculty interviewed found it necessary to use information sources external to Hamline University in order to satisfy their needs for materials and services. Overall, seventeen sources were mentioned. Many of these sources are in the Twin Cities; however, some are located in other areas of the country. The two most frequently used sources are professional meetings and the University of Minnesota Library. Several faculty members have built up sizable personal collections of books and journal subscriptions. In a sense these collections reduce the demand on the central collection by providing an additional source of informational materials for professors and students to draw upon. (Note: most faculty members indicated that they were willing to make materials in collections available to colleagues and selected students.) The maintenance, updating, and expansion of these collections, however, constitutes a substantial personal expense. $^{8}$

About the students the researchers said:

The students working on independent study projects use a much wider range of material selection aids than the regular students. The regular student who is working on a term paper relies primarily on the Hamline University Library card catalog

"Anne W. Schumacher, "A Small College Information System: an Analysis and Recommendations." A report submitted to Hamline University, St. Paul, Minnesota, under NSF Grant No. GN-624. p. III-2.

${ }^{8}$ Ibid., p. II-6. 
and the Readers' Guide to identify and select relevant material, while the independent study student uses several additional sources including principally abstract journals, special bibliographies, and journal article citations. ${ }^{9}$

The interviews indicated that both students and faculty are having information problems, and that the campus library is not meeting the information needs of the more sophisticated library users, even among the students.

\section{Conclusion}

The researchers drew two interesting conclusions from their work. Of perhaps slightly less importance to the immediate development of the campus library, yet perhaps of the greatest long-range importance, was this statement in the Schumacher report.

It is apparent that if the librarian wants the faculty to make use of the range of available services, he and his staff must market them; just indicating that certain services are available is not a sufficient stimulus for getting the faculty to use the services. This is, in part, due to the low expectation of faculty concerning the adequacy with which bibliographic service could be accomplished by the library. In order to overcome this attitude, which may or may not be well-founded, it would be necessary for the library staff to demonstrate to the faculty that this is not the case; e.g., bibliographies relating to various subject fields could be compiled on a trial basis and presented to selected faculty for review and evaluation. ${ }^{10}$

Two of the points in this statement pinpoint problem areas for librarians. In adjusting to modern conditions it seems that one of the areas of which librarians have in part failed to keep abreast is public relations, user liaison, "marketing," or whatever other term may be used. But basically some librarians have

\footnotetext{
Ibid., p. II-7.
}

${ }^{10}$ Ibid., p. III-12. not related the function of the library to modern problems. As a result there seems often to be little or no relationship in the mind of the user between his information problems and the library.

At the same time, by their inability to relate publicly the campus library to modern problems, librarians find themselves with inadequate staffs and facilities to provide increased information service to their users. Yet this very service, according to the Schumacher report, is one way in which librarians could demonstrate their relevance to users. For librarians to follow this course would require that they convince their funders that they are really relevant to information problems. It would seem from this dilemma that librarians need to develop public relations programs which indicate the importance of libraries to information problems.

Of more immediate importance to college libraries were the suggestions of the researchers for the future of the campus library. The researchers rejected the traditional solution of campus libraries to the problem of providing adequate information service. For Hamline University:

One approach to expanding the informational base of the library is to substantially increase or build up the permanent collection; that is, make the library responsible for acquiring, processing, and storing all the materials that are currently required or might possibly be required in the future. This approach is rejected because it does not meet the following criteria:

1) Acquisitions and operating costs: the cost associated with the purchase of materials would require a far larger budget than appears to be probable in the near future.

2) Growth potential or adaptability to structural characteristics: the current and planned for library facilities do 
not provide enough storage space for all the materials that would have to be acquired.

3) Marketability or applicability of acquired materials to a wide range of information needs: the rate of turnover in the faculty and student body places additional purchasing requirements on the library. Over 40 per cent of the faculty has been at Hamline for less than four years. As the composition of the faculty shifts, the requirements for information change. In order to provide needed information, the library will have to purchase large numbers of informational materials in highly specialized areas. When faculty members leave, the library may be faced with the problem of storing a substantial amount of material which is of little or no value to its other users. ${ }^{11}$

Basically the researchers concluded that it is not economically feasible for the campus library to provide ever-expanding collections of material to meet the campus information needs. Their proposal is to solve the problem by emphasizing the campus library as an information switching center. The campus library traditionally has performed this role in limited ways. The interlibrary loan program for college faculty is the best known of such programs. In the Minneapolis-St. Paul area the seven college libraries have also established a direct borrowing system for their undergraduates. The researchers propose, however, that the college library go further than this.

The library could expand its base of informational resources by operating as a clearinghouse or switching center for materials services. As a clearinghouse, the library obtains the needed materials and services from other libraries or information centers and disseminates these materials to the faculty and students. These materials could be of several types: some examples

${ }^{11}$ Ibid., p. IV-2. include specialized books or sections of books, photocopies of journal articles, technical reports, pamphlets, abstracting bulletins, tables of contents of selected journals and specialized bibliographies.

There are three major advantages associated with having the library function as a clearinghouse. First, it enables the library to have a large pool of informational materials available to it without having the processing storage requirements associated with acquiring information for the permanent collection. . . . Second, by dealing with information sources and services which are based on large, comprehensive collections of material, the library can make available information search services and current awareness services which it could not otherwise provide without significantly increasing its own information resources and acquiring the necessary personnel and equipment (e.g., most of the current awareness services are computer based). Third, since the needs for specialized and in-depth material can be satisfied through the clearinghouse, the book budget can be directed towards purchasing only those materials that are needed by undergraduate students in completing their course requirements; that is, the budget can be concentrated on developing a good "core" collection rather than also attempting to meet specialized requirements associated with independent study and research projects. Considering the library as an information clearinghouse represents a significant shift from traditional operations. The library rather than the user is made responsible for identifying sources of informational materials and services and for compiling bibliographies and conducting literature searches to meet stated requirements. ${ }^{12}$

In more traditional library language the switching center concept consists of three major elements. First, there is the traditional concept of a core collection, which would directly support the curriculum of the college. Hopefully such a core collection would be selected with increasing sophistication, so that there

${ }^{12}$ Ibid., pp. IV-3-4. 
would be few unused items in the collection. Such a collection would probably contain many items in multiple copies and also be heavily weeded to keep abreast of changing user needs for such materials.

The second role of the campus library would be to serve as a transmission channel between the sources of information and the students and faculty. The information transmitted would be unrestricted as to format and location. The information could be purchased outright, either as available publications or reproduced copies, or borrowed from cooperating institutions. If the material is borrowed, it would seem advisable that the arrangement be one which is beneficial to both the borrowing and lending institutions.

The third element would be the selective dissemination of information to faculty and students as seems appropriate. For the faculty the service would consist of information which related to the courses they were teaching and the research they were conducting. For the students the service would be organized around courses which required information support of considerable scope. Such a service would enable the students to devote maximum time to using information rather than obtaining it.

The research project generally indicated that the college library faces a considerable problem in providing the needed information on campus. It also indicated that the traditional attack on the problem, the building of large campus collections, is not an economically feasible approach to the problem. Nor does the trend in higher education indicate a lessening of the information problem. There does seem to be a trend toward more individualized and independent study, with the emphasis on the student learning to pose problems and find solutions in various subject disciplines, rather than amassing a basic store of information which will provide him with a lifelong "education." If the college library is to become a significant factor in modern higher education as it is now developing, the library must develop an ability to relate the mass of information generated in modern society to the information needs of faculty and students.

Based on the results of this study a pilot study is now being conducted on the Hamline campus with funding from the National Science Foundation. This pilot study deals with course preparation and conduct by four faculty members with the objective of establishing methods for dealing with information needs emanating therefrom. Such methods may permit the development of an effective and economically feasible campus information system which will meet the sophisticated information needs of the faculty and the slightly less sophisticated needs of the students. 